\title{
Stress, Psychological Resources, and HPA and Inflammatory Reactivity During Late Adolescence
}

\author{
JESSICA J. CHIANG,${ }^{a}$ AHRA KO,${ }^{b}$ JULIENNE E. BOWER, ${ }^{c}$ SHELLEY E. TAYLOR, ${ }^{c}$ MICHAEL R. IRWIN,${ }^{c}$ AND \\ ANDREW J. FULIGNI ${ }^{c}$ \\ ${ }^{a}$ Northwestern University; ${ }^{b}$ Los Angeles County Department of Mental Health; and ${ }^{c}$ University of California, Los Angeles
}

\begin{abstract}
Psychosocial stress during childhood and adolescence is associated with alterations in the hypothalamic-pituitary-adrenal (HPA) axis and with heightened inflammation, both of which are implicated in poor health; however, factors that may protect against these effects relatively early in life are not well understood. Thus, we examined whether psychosocial resources protect against stress-related alterations in the HPA axis and heightened inflammation in a sample of 91 late adolescents. Participants completed measures of various stressors (major life events, daily interpersonal stress, early adversity), and psychosocial resources (mastery, optimism, self-esteem, and positive reappraisal). They also completed the Trier Social Stress Test and provided saliva and blood samples for the assessment of cortisol and interleukin-6 reactivity. Each of the stressors was associated with lower cortisol reactivity. Additionally, associations with major life events and daily stress were moderated by psychological resources, such that more life events and daily stress were associated with decreased HPA reactivity among adolescents with lower levels of psychological resources, but not among those with higher levels of psychological resources. This pattern of findings was observed only for cortisol reactivity and not for interleukin-6 reactivity. Findings suggest that psychological resources may counteract the effects of certain adversity-related decreases in cortisol reactivity.
\end{abstract}

Psychosocial stress during childhood and adolescence can have immediate and long-term effects on both mental and physical health, increasing risk for numerous conditions that range from mood and anxiety disorders to upper respiratory infections to premature mortality (Brown et al., 2009; Cohen, Doyle, Turner, Alper, \& Skoner, 2004; Demakakos, Pillas, Marmot, \& Steptoe, 2016; Miller, Chen, \& Parker, 2011; Repetti, Taylor, \& Seeman, 2002; Syed \& Nemeroff, 2017). These associations are thought to be driven in part by gradual changes in the stress response system, specifically in the hypothalamic-pituitary-adrenal (HPA) axis and in inflammatory processes (Ehrlich, Miller, \& Chen, 2016; Heim \& Binder, 2012; Slavich \& Irwin, 2014). Stress activates the HPA axis, resulting in secretion of the hormone cortisol, and increases inflammation. These biological responses to stress promote short-term adaptation to challenging circumstances.

This research was supported by funding from the Eunice Kennedy Shriver National Institute of Child Health and Human Development (R01HD062547), UCLA California Center for Population Research funded by the National Institute of Child Health and Human Development (R24HD041022), and the UCLA Older Americans Independence Center funded by the National Institute of Aging (P30-AG028748), UCLA Cousins Center for Psychoneuroimmunology, University of California Institute for Mexico and the US, American Psychological Association, and Division 38 of the American Psychological Association. The authors' efforts were supported by the National Heart, Lung, and Blood Institute Grant F32-HL134276 (to J.J.C.).

Address correspondence and reprint requests to: Jessica J. Chiang, Northwestern University, 1801 Maple Avenue, Suite 2450, Evanston, IL 60201; E-mail: jessica.chiang@northwestern.edu.
However, repeated or chronic activation of these responses can interfere with later HPA axis functioning and inflammatory processes in ways that compromise long-term health (McEwen \& Seeman, 1999).

A substantial body of work has linked various childhood and adolescent stressors, including socioeconomic disadvantage, maltreatment, harsh parenting, and parental separation or loss, to alterations in the HPA axis and to heightened inflammation. Outcomes of HPA axis functioning include the components of the diurnal rhythm of cortisol (i.e., cortisol awakening response, diurnal slope, and waking and bedtime cortisol levels) and responses to acute psychosocial stress. Previous studies have linked childhood and adolescent stress to both heightened and dampened levels of cortisol, which may be due to differences in stressor characteristics and HPA axis measurement (Chiang, Taylor, \& Bower, 2015; Repetti, Robles, \& Reynolds, 2011). Seemingly discrepant findings may also reflect the notion that because excessive exposure to glucocorticoids can be detrimental, hypocortisolism may emerge after sustained periods of hypercortisolism as a counterregulatory mechanism (Fries, Hesse, Hellhammer, \& Hellhammer, 2005; Miller, Chen, \& Zhou, 2007). Indeed, with respect to HPA responses to acute stress, studies have consistently linked chronic or repeated stress to dampened cortisol responses (Bunea, Szentágotai-Tătar, \& Miu, 2017; Cărnuţăă, Crişan, Vulturar, Opre, \& Miu, 2015; Carpenter et al., 2007; Carpenter, Shattuck, Tyrka, Geracioti, \& Price, 2011; Elzinga et al., 2008; Engert et al., 2010; Janusek, Tell, Gaylord-Harden, \& Mathews, 2017; Kraft \& Luecken, 
2009; Lovallo, 2013; MacMillan et al., 2009), a pattern that has also been observed in individuals with posttraumatic stress disorder, chronic fatigue syndrome, and fibromyalgia (Heim, Ehlert, \& Hellhammer, 2000). Dampened cortisol reactivity to stress has also been associated with poorer lung function, decreased antibody responses to vaccination, and greater adiposity (Carroll et al., 2012; de Rooij, 2013; Phillips, Carroll, Burns, \& Drayson, 2005). In addition to its links to HPA axis alterations, childhood and adolescent stress has also been related to heightened levels of circulating inflammatory markers in adulthood (Baumeister, Akhtar, Ciufolini, Pariante, \& Mondelli, 2016; Coelho, Viola, Walss-Bass, Brietzke, \& Grassi-Oliveira, 2014). Studies of youth have yielded more mixed results, suggesting potential delayed effects on systemic inflammation (Slopen, Koenen, \& Kubzansky, 2012; Slopen, Kubzansky, McLaughlin, \& Koenen, 2013). Importantly, heightened inflammation is implicated in numerous age-related chronic conditions, including heart disease and certain cancers (Brydon \& Steptoe, 2005; Choy, 2012; Elinav et al., 2013; Libby, 2006; Wellen \& Hotamisligil, 2005).

Although much research has linked childhood and adolescent stress to HPA alterations and heightened inflammation, factors that protect against these are not completely understood. Previous research has pointed to warm and supportive relationships as important protective factors (Brody, Yu, \& Beach, 2016; Carroll et al., 2013; Chen, Miller, Kobor, \& Cole, 2011), but less is known about individual psychological characteristics that may similarly counteract the biological effects of early stress. Theoretical models purport several individual psychological characteristics, collectively known as psychological resources, that promote resilience in the face of adversity; these include constructs such as mastery or a sense of control over one's life, purpose in life, positive affect, optimism, self-esteem, and the ability to positively reappraise negative emotions and situations (Chen \& Miller, 2013; Gallo, de los Monteros, \& Shivpuri, 2009; Taylor \& Seeman, 1999). These individual characteristics have independently and together been associated with lower risk for clinical health outcomes such as mortality and cardiovascular disease (Carver, Scheier, \& Segerstrom, 2010; Lundgren, Garvin, Jonasson, Andersson, \& Kristenson, 2015; Stamatakis et al., 2004; Surtees, Wainwright, Luben, Khaw, \& Day, 2006; Taylor \& Broffman, 2011). They have also been shown to buffer against chronic stress-related increases in inflammation and delayed blood pressure recovery from subsequent acute stress (Boylan, Jennings, \& Matthews, 2016; Elliot \& Chapman, 2016).

The majority of these studies have focused on adults, raising the question of whether psychological resources can similarly buffer against the adverse effects of chronic or repeated stress during earlier life stages. Adolescence may be an especially important focal point for several reasons. First, the adolescent years are marked by an increase in stress. Demands across domains (school, peers, and family) are known to increase during this time, and adolescents have reported similar or higher levels of psychosocial stress than adults (American Psychological Association, 2014). Second, in addition to facing increasing stress, research suggests that sensitivity to the environment increases during adolescence, potentially rendering adolescents more vulnerable to the effects of stress (Blakemore \& Mills, 2014; Somerville, 2013; Spear, 2009). Evidence for this notion comes from studies showing that adolescents exhibit greater negative affective and neurobiological responses to social threat compared with children and adults (Gunnar, Wewerka, Frenn, Long, \& Griggs, 2009; Sebastian, Viding, Williams, \& Blakemore, 2010; Stroud et al., 2009). Last, the foundations of future adult health may be set during adolescence. The idea here is that with rapid neurobiological and psychosocial development that facilitates the transition into an independent, productive adult, adolescent experiences can not only directly shape biological patterns of functioning, but also modify health trajectories initiated in childhood and contribute to the adoption of long-term health behaviors (Del Giudice, Ellis, \& Shirtcliff, 2011; Tottenham \& Galván, 2016; Viner et al., 2012).

Studies examining whether psychological resources buffer against the negative health effects of chronic stress during adolescence have found that optimism in combination with meaning in life attenuated the association between socioeconomic disadvantage and obesity, cardiometabolic risk, and inflammatory processes (Chen, Lee, Cavey, \& Ho, 2013; Chen, McLean, \& Miller, 2015; Kallem et al., 2013). However, such studies are few, and buffering effects on the HPA axis have not been examined. Yet, as described previously, the HPA axis is thought to be an important pathway linking early stress to poor health. Additionally, studies have focused on only a single form of adversity, namely socioeconomic disadvantage. However, youth encounter a variety of stressors in their lives. Furthermore, more mundane and less severe stressors occurring in everyday life (e.g., conflict, work deadlines), in addition to other various chronic stressors (e.g., childhood maltreatment, major life events), have been linked to poor health outcomes and compromised biological functioning (Chiang, Eisenberger, Seeman, \& Taylor, 2012; DeLongis, Folkman, \& Lazarus, 1988; Dietz et al., 2013; Luecken \& Appelhans, 2006; Miller et al., 2011; Repetti et al., 2011; Stawski, Cichy, Piazza, \& Almeida, 2013; Stone et al., 1994). Whether psychological resources protect against the health-related effects of these other stressors is not entirely clear.

The overall purpose of the present study was to examine whether various stressors were associated with HPA axis alterations and heightened inflammation during late adolescence, and whether psychological resources (mastery, self-esteem, optimism, and the tendency to positively reappraise negative situations) mitigated these associations. We focused on cortisol and interleukin (IL)-6 reactivity to a standard laboratory stress task as indices of HPA axis functioning and inflammatory processes, respectively. We examined several types of stressors, including major life events in the past year, daily negative social interactions across a 15-day period, 
and the early psychosocial family climate. Given that prior work has tied each of these stressors to health outcomes and biological functioning in both youth and adults (Carroll et al., 2013; Chiang et al., 2016; Fuligni et al., 2009; Kershaw et al., 2014; Loucks, Almeida, Taylor, \& Matthews, 2011; Miller \& Chen, 2010; Pyykkönen et al., 2010; Stroud, Chen, Doane, \& Granger, 2016), we did not hypothesize any differential effects according to stressor type. Instead, we hypothesized that all three types of stress would be associated with suboptimal biological profiles, as evidenced by dampened cortisol and heightened IL-6 responses to acute stress. We further hypothesized significant interactions among each of the three types of stress and psychological resources, such that those reporting greater levels of stress and lower levels of psychological resources would exhibit reduced cortisol and elevated IL-6 reactivity. These associations were expected to be attenuated among those who reported stress but had higher levels of psychological resources. Given that our sample included Latino and European-American adolescents, exploratory analyses examined whether there were any ethnic differences in stress associations with cortisol and IL- 6 responses and in the potential buffering role of psychological resources. Socioeconomic status, family values, and rates of racial discrimination are known to differ between these two ethnic groups (Fuligni, Tseng, \& Lam, 1999; Greene, Way, \& Pahl, 2006; Sabogal, Marín, Otero-Sabogal, Marín, \& Perez-Stable, 1987; Semega, Frontenot, Kollar, \& Bureau, 2017), which may translate to differential effects of stress and its interactions with psychological resources on biological responsivity.

\section{Method}

\section{Participants}

Participants were 18- to 20-year-old adolescents $(n=91$; $M_{\text {age }}=18.37, S D=.51 ; 57 \%$ female) drawn from a larger sample of 248 adolescents $\left(M_{\text {age }}=18.31, S D=.77\right)$ partaking in the second wave of a three-wave longitudinal study on the psychosocial contributions to the development of early health risk from mid-adolescence to early adulthood. During the first wave of the larger parent study, 316 tenth- and eleventh-grade students $\left(M_{\text {age }}=16.40, S D=.74\right)$ were recruited, 214 of whom participated in the second wave 2 years later. During the second wave, 34 new participants were added to refresh the sample. Two years after the second wave, 180 participants $\left(M_{\text {age }}=20.29, S D=.74\right)$ from Wave 1 and/or Wave 2 provided data during the third and final wave.

Data collection of the larger study involved a home visit during which participants completed a series of questionnaires and a 15-day daily diary protocol. After completing the Wave 2 protocol, participants were prescreened to ensure that they identified as Latino or European-American (other ethnicities were excluded because of insufficient numbers in the larger study) and were at least 18 years of age. Prescreening was based on responses to demographic questionnaires collected in the larger parent study. Eligible individuals were contacted via telephone, and those who responded $(n=169)$ were given information on the current experimental study and invited to participate. Individuals expressing interest were scheduled for a laboratory visit and instructed to refrain from eating or drinking anything (except water) the hour prior to the visit. Ninety-one participants, 79 of whom were from the original Wave 1 sample and 12 of whom were from the pool of newly added participants at Wave 2, completed the laboratory visit an average of $5.5(S D=2.7$, range $=$ 1.4-12.2) months after they completed Wave 2 of the parent study. Participants in the present study did not differ from the larger Wave 2 sample on age, gender, parent education, and ethnicity (all $p s>$.156). They also did not differ on major life events and daily interpersonal stress (all $p$ s $>.173$ ), which were assessed as part of the larger parent study.

The subsample in the current study were from EuropeanAmerican (37.36\%) and Latino backgrounds (62.64\%). Primary caregivers reported on annual household income as well as their own and spouse's highest level of education on an 11-point scale $(1=$ some elementary school, $11=$ graduated from medical law, or graduate school). Education across parents was averaged. Across the study sample, median household income was $\$ 79,000$ (range $=\$ 11,000$ $\$ 350,000)$. Approximately $14.44 \%$ of participants had parents with less than a high school diploma, $7.78 \%$ had at least one parent with a high school diploma, 38.89\% had at least one parent who completed vocational trade school or some college, $23.33 \%$ had at least one parent with a college degree, and $15.57 \%$ had at least one parent who completed some or all of graduate or professional school.

\section{Procedure}

Participants arrived at the University of California, Los Angeles (UCLA), Clinical and Translational Research Center and provided informed written consent and anthropometric measures. A nurse then inserted an indwelling intravenous catheter in the antecubital vein of the nondominant arm, after which participants viewed a neutral-content video for $20 \mathrm{~min}$ to facilitate acclimation to the testing environment. The first saliva and blood samples were collected after this baseline period. Participants then completed the Trier Social Stress Task (TSST), a well-established acute laboratory-based social stressor that activates the HPA axis and increases inflammation (Kirschbaum, Pirke, \& Hellhammer, 1993; Steptoe, Hamer, \& Chida, 2007). Participants delivered a 5-min impromptu speech on why they were the best candidates for their ideal jobs in front of an evaluative panel of expert interviewers consisting of research assistants trained to provide nonverbal negative feedback. Participants were given $5 \mathrm{~min}$ to prepare for their speech. Immediately after delivering their speech, participants performed a 5-min mental arithmetic task involving progressively subtracting 13 from 2,935 while the evaluative panel urged them to go more quickly and perform more accurately. After the TSST, participants 
provided five additional saliva samples (immediately and 30, 45, 60, and 75 min post-TSST onset) and three additional blood samples (30, 60, and 90 min post-TSST onset). After the final blood sample was collected, participants were debriefed and compensated. All visits were conducted between the hours of 12 and $6 \mathrm{pm}$, and the UCLA institutional review board approved all procedures.

\section{Measures}

Major life events. During the second wave visit of the parent study, participants completed a major life event checklist. They reported on whether they had experienced any of 21 events across the domains of family, friends, and school within the past 12 months. Items were adapted from previously used measures of stressful events that have been linked to negative outcomes (Conger et al., 2002; Hammen, 1991). Example items included parents divorced or separated, family member became seriously ill, a close friend moved quite far away, having a serious falling out or ending a friendship with a close friend, being suspended or expelled in school, and grades in school went down a lot. Affirmative responses were summed across items.

Daily interpersonal stress. Participants also completed a daily diary protocol during the second wave visit of the parent study. Each night for 15 consecutive evenings, participants reported on whether they had experienced any of 8 negative social interactions across the contexts of family, peers, and school. Items were argued with a parent, argued with another family member, argued with a friend, punished by a parent, parents argued, something bad happened to a family member, had an argument or was punished by an adult at school, and was insulted, threatened, or made fun of by someone at school. These items were selected because they have previously been shown to be stressful for adolescents (Chung, Flook, \& Fuligni, 2009; Fuligni et al., 2009; Nishina \& Juvonen, 2005). Consistent with previous research on daily stress (Chiang et al., 2016; Grzywacz, Almeida, \& McDonald, 2002; Sin, Graham-Engeland, Ong, \& Almeida, 2015), affirmative responses were summed and recoded as 0 or 1 for each day to indicate whether any 1 of the stressors occurred that day. The average of recoded scores across days was subsequently computed to indicate the proportion of days that at least 1 stressor occurred.

Early adversity. The Risky Families questionnaire (Taylor, Lerner, Sage, Lehman, \& Seeman, 2004) was used to measure early adversity and was administered during the laboratory visit. Specifically, the Risky Families questionnaire assesses the family psychosocial climate in which participants grew up when they were 5 to 15 years old. On a 5-point scale $(1=$ not at all to $5=$ very often $)$, participants indicated how frequently they experienced conflict, violence, corporal punishment, parental affection, neglect, and chaos. The Risky Families questionnaire has been widely used in previous research and aligns with clinical interviews assessing early life stress. Items framed positively were reverse-coded and scores across items were averaged. The scale demonstrated good internal reliability in the present sample $(\alpha=.84)$.

HPA reactivity. Six saliva samples were collected using oral swabs (Salimetrics) throughout the laboratory visit. They were collected immediately after the neutral-content video (baseline) and TSST, and 30, 45, 60, and $75 \mathrm{~min}$ after TSST onset. Samples were stored at $-80^{\circ} \mathrm{C}$ until transported on ice to the Laboratory of Biological Psychology at the Technical University of Dresden, Germany, where they were assayed for cortisol in duplicate using high-sensitivity chemiluminescence-immunoassays (IBL, International, Hamburg, Germany). Intra- and interassay coefficients of variations were $<10 \%$. Outlier screening revealed a total of 10 samples across time points that had cortisol values greater than 3 standard deviations (SDs) from their respective means. These values were Winsorized and replaced with the value at 3 SDs. Cortisol values were then natural log-transformed to correct for their skewed distributions. We previously reported that the TSST activated the HPA axis, as evidenced by a significant increase in cortisol from baseline to 30 and $45 \mathrm{~min}$ after TSST (Chiang, Bower, Irwin, Taylor, \& Fuligni, 2017).

Inflammatory reactivity. Four blood samples of $6 \mathrm{ml}$ were collected at baseline, and 30, 60, and 90 min after TSST onset into ethylenediaminetetraacetic acid lavender-top tubes. Samples were placed on ice immediately after collection, after which they were centrifuged, aliquoted into plasma samples, and stored at $-80^{\circ} \mathrm{C}$. After data collection was completed, samples were assayed in duplicate for IL-6 using the Quantikine high sensitivity human IL-6 ELISA kits (R\&D Systems, Inc., Minneapolis, MN) by the UCLA Cousins Center Inflammatory Biology Core. Intra- and interassay coefficients of variability were $<7 \%$. Outlier screening revealed a total of 11 samples across time points that had IL-6 values greater than 3 SDs from their respective means. These values were Winsorized and replaced with the value at 3 SDs. All values were natural log-transformed given the skewed distribution. As reported previously (Chiang et al., 2017), the TSST was effective in eliciting an inflammatory response, with participants exhibiting a $34 \%$ average increase in IL-6 from baseline to $90 \mathrm{~min}$ after TSST onset.

Psychological resources. Measures of psychological resources were completed during the laboratory visit and assessed perceived control, optimism, self-esteem, and positive reappraisal. Perceived control was assessed using the 7-item Pearlin Mastery Scale (Pearlin \& Schooler, 1978). Participants indicated the extent to which they agreed with statements such as: "There is little I can do to change many of the important things in my life (reverse coded)," and "What happens to me in the future mostly depends on me," using a 4-point scale ( $1=$ strongly disagree, $4=$ strongly agree $)$. In the current study, internal consistency was adequate $(\alpha=.74)$. 
Dispositional optimism was assessed using the 6-item Life Orientation Test (Scheier, Carver, \& Bridges, 1994). Using a 5 -point scale $(0=$ strongly disagree, $4=$ strongly agree $)$, participants rated the degree to which they agreed with each item. Example items include "In uncertain times, I usually expect the best" and "Overall, I expect more good things to happen to me than bad." This scale demonstrated good internal reliability in the present study $(\alpha=.83)$.

Self-esteem was assessed using the 10-item Rosenberg Self-Esteem Scale (Rosenberg, 1965). Participants rated items such as, "I feel that I have a number of good qualities" and "On the whole, I am satisfied with myself," on a 4-point scale $(0=$ strongly agree, $3=$ strongly disagree $)$. Internal consistency of this scale was high $(\alpha=.93)$.

Positive reappraisal was assessed using the cognitive reappraisal subscale from the Emotion Regulation Questionnaire (Gross \& John, 2003). Using a 7-point scale $(1=$ not at all, 7 $=a(o t)$, participants indicated the extent to which they agreed with statements such as "To feel less negative emotion, I change what I think about" and "When I'm faced with a stressful situation, I make myself think about it in a way that helps me stay calm." The Emotion Regulation Questionnaire has been wellvalidated and internal consistency in the present sample was high $(\alpha=.88)$.

Negatively worded items on each scale were reverse coded, such that higher scores indicated greater mastery, optimism, self-esteem, and positive reappraisal. Items were then summed for each scale. Principal-components analysis indicated that a single component explained $61.2 \%$ of the variance. Factor loadings were .83 for mastery, .83 for optimism, .73 for self-esteem, and .72 for reappraisal. Thus, we averaged standardized scores of the four scales to create a composite score indexing psychological resources.

Potential covariates. Sociodemographic characteristics (age, gender, ethnicity, socioeconomic status), health behaviors (exercise, caffeine consumption, cigarette smoking), adiposity (waist circumference), use of oral contraceptives, and time of day were considered as potential covariates given that these factors have been previously related to levels of cortisol and/or IL-6 (DeSantis et al., 2007; Dowd, Simanek, \& Aiello, 2009; Jacks, Sowash, Anning, Mcgloughlin, \& Andres, 2002; Lovallo et al., 2005; O'Connor et al., 2009; Uhart, Chong, Oswald, Lin, \& Wand, 2006).

During the second wave visit, participants reported their own ethnicity and gender. Their parents reported participants' date of birth, from which age was computed, and their own and spouse's educational attainment. Educational attainment was averaged across parents to index family socioeconomic status. Waist circumference was assessed twice at the midpoint between the iliac crest and lower rib and averaged. During the laboratory visit, study experimenters recorded participants' time of arrival, and participants reported on the number of caffeinated beverages consumed that day, whether they smoked cigarettes during the past week (yes/ no), and whether they currently use oral contraceptives (yes/no). Additionally, for three consecutive mornings before the laboratory visit, participants reported on whether they engaged in physical activity the previous day and the total number of days exercised was computed.

\section{Analytic approach}

Selection of covariates. Bivariate correlations among potential covariates and cortisol and IL-6 at each time point were examined to identify the panel of covariates to be included in primary analyses. Gender, parental education, time of day, exercise, smoking, and use of oral contraceptives were significantly or marginally associated with at least one of the cortisol measures across time points (all $r=-.40$ to .30 , all $p$ s $<.06$ ). Thus, these were included as covariates in all models with cortisol as the outcome. For IL-6, age, gender, parent education, ethnicity, and waist circumference showed marginal or significant correlations with at least one IL-6 measure across time points (all $r=-.21$ to .47 , all $p \mathrm{~s}<.06$ ) and were therefore included as a covariate in models with IL-6 as the outcome. Models with and without covariates yielded similar results.

Primary analyses. Multilevel modeling was used to conduct analyses given repeated measurements within individuals. Level 1 modeled within-person changes in cortisol and IL6 as a function of time, whereas Level 2 modeled betweenperson differences in cortisol and IL- 6 responses based on experiences of stress (i.e., major life events, daily interpersonal stress, and early adversity), psychological resources, and their interactions. The intercepts in models represent baseline levels of cortisol and IL-6. Models with cortisol as the outcome included both a linear and a quadratic term for time given that sampling times captured cortisol reactivity as well as recovery (Chiang et al., 2017; Dickerson \& Kemeny, 2004). The linear term for time represents the rate of change in cortisol, whereas the quadratic term for time represents how the rate of change increases or decreases across time, or in other words, the curvature of cortisol responses. Thus, increased cortisol reactivity is reflected as a positive value for the linear term, and a slowing rate of cortisol increases (i.e., cortisol peaks then declines) is reflected as a negative value for the quadratic term. Models with IL- 6 as the outcome only included a linear term for time given that sampling times captured only reactivity to the TSST, because IL-6 requires a longer period to return to baseline (Chiang et al., 2017; Marsland, Walsh, Lockwood, \& John-Henderson, 2017).

We first tested the main effects of stress and psychological resources on cortisol and IL-6 response trajectories by examining the cross-level interactions between stress and time and between psychological resources and time. As reported in the following "Results" section, significant stress by time interactions emerged. These interactions were followed by tests of simple slopes in which the effect of time on responses to the TSST were examined among individuals above and below one-half of a standard deviation from the mean of major life 
events (low: $n=21$; high: $n=21$ ), daily interpersonal stress (low: $n=29$; high: $n=30$ ), and early adversity (low: $n=32$; high: $n=22$ ).

We then tested whether psychological resources protected against the effects of stress by examining the three-way interactions among stress, psychological resources, and time. Significant interactions indicate that biological responses varied as a function of stress at varying levels of psychological resources. Observed interactions were followed by tests of simple interactions in which two-way stress by time interactions were examined separately in individuals above $(n=33)$ and below $(n=23)$ one-half of a standard deviation from the mean of psychological resources.

In all analyses, interaction effects were probed at one-half of a standard deviation above and below the mean of the moderator of interest because the number of individuals above and below one standard deviation were much fewer. All continuous predictor and covariate variables were grand mean-centered and separate models were tested for each measure of stress. Because major life events and daily interpersonal stress were assessed at varying times before the laboratory visit, we also assessed whether the duration between the second-wave visit of the parent study and the laboratory visit altered results. Results were unchanged when time between parent study and laboratory visit was added as a covariate. Therefore, results from models without this variable are reported.

Missing data. Rates of missing data were low for variables included in analyses. Variables that had missing data included IL-6 at all time points, parent education, and daily family stress. For IL-6, only 7 of the 364 (1.9\%) samples had missing data. Only one $(1.1 \%)$ participant had missing data on parent education, and only three (3.3\%) participants had missing data on daily interpersonal stress. In all models, full information maximum likelihood estimation was used.

\section{Results}

Descriptive statistics are presented in Table 1 and bivariate correlations are displayed in Table 2. Overall, adolescents experienced a few major life events, had negative social interactions on $24 \%$ of days (i.e., 3.6 days), and experienced fairly low levels of early adversity. As expected, more major life events, daily interpersonal stress, and early adversity were positively correlated with one another and negatively correlated with psychological resources. Of the different stressors, only greater early adversity was associated with lower cortisol. Psychological resources were also not associated with cortisol. Neither stress nor psychological resources was correlated with IL-6.

\section{HPA reactivity}

Major life events. As shown in Table 3 (column 1), neither major life events $(p=.623)$ nor psychological resources $(p=$ .870) were associated with baseline levels of cortisol. Cortisol reactivity to the TSST was also not modulated by psychologi-
Table 1. Sample characteristics and descriptive statistics of study variables.

\begin{tabular}{lcc}
\hline \hline Variable & Mean $(S D)$ & Range \\
\hline Age, y & $18.37(.51)$ & $18.00-20.00$ \\
Female, \% & 57 & \\
Latino, \% & 63 & \\
Parent education & $7.44(2.01)$ & $2.00-10.50$ \\
Major life events & $3.15(2.04)$ & $.00-12.00$ \\
Daily interpersonal stress & & \\
$\quad$ proportion of days) & $.24(.21)$ & $.00-0.93$ \\
Early adversity & $1.92(.60)$ & $1.00-3.92$ \\
Psychological resources & $.00(.78)$ & -2.47 to 1.26 \\
Cortisol & $13.03(39.06)$ & -74.24 to 94.67 \\
$\quad$ Baseline & $16.84(15.69)$ & $3.51-111.16$ \\
Post-TSST & $17.76(13.81)$ & $4.69-109.53$ \\
$\quad+30$ min & $24.60(15.40)$ & $5.68-90.47$ \\
$\quad+45$ min & $19.71(11.95)$ & $4.24-71.57$ \\
$\quad+60$ min & $15.82(8.11)$ & $4.09-45.41$ \\
$\quad+75$ min & $14.20(6.98)$ & $2.10-41.86$ \\
IL-6 & & \\
$\quad$ Baseline & $1.47(1.39)$ & $.34-7.53$ \\
$\quad+30$ min & $1.44(1.29)$ & $.27-7.54$ \\
$\quad+60$ min & $1.70(1.49)$ & $.35-9.28$ \\
$\quad+90$ min & $1.97(1.65)$ & $.41-8.36$ \\
\hline \hline
\end{tabular}

Note: Cortisol and IL-6 reflect raw, un-Winsorized values.

cal resources (linear: $p=.297$; quadratic: $p=.201$ ). However, there was a significant interaction between major life events and time (linear: $p=.005$; quadratic: $p=.006$ ). Follow-up tests revealed that adolescents who experienced more major life events exhibited smaller cortisol responses (linear: $b(S E)=.07(.06), p=.195$; quadratic: $b(S E)=-.03(.01)$, $p=.006)$ relative to those who experienced fewer major life events (linear: $b(S E)=.21(.05), p<.001$; quadratic: $b(S E)=-.05(.01), p<.001)$.

The association between major life events and cortisol responses were modulated by psychological resources, as evidenced by the significant interaction between major life events, psychological resources, and time (linear: $p<.001$; quadratic: $p=.001$; Table 3 , column 2). At lower levels of psychological resources, cortisol responses varied as a function of major life (linear: $b(S E)=-.07(.02), p=.002$; quadratic: $b(S E)=.01(.004), p=.008)$. By contrast, at higher levels of psychological resources, major life events were not associated with cortisol responses (linear: $b(S E)=.01(.02)$, $p=.715$; quadratic: $b(S E)=.0002(.004), p=.968)$. Visualization of these simple interaction effects shows that among individuals with low psychological resources (Figure 1a), those with more major life events exhibit smaller cortisol responses relative to their peers who report fewer major life events. However, among those with high psychological resources (Figure 1b), cortisol responses of those with more major life events more closely resemble those with fewer major life events.

Daily interpersonal stress. Paralleling findings for major life events, daily interpersonal stress operationalized as propor- 
Table 2. Bivariate correlations among primary study variables.

\begin{tabular}{|c|c|c|c|c|}
\hline Variable & $\begin{array}{l}\text { Major life } \\
\text { events }\end{array}$ & $\begin{array}{l}\text { Daily interpersonal } \\
\text { stress }\end{array}$ & $\begin{array}{c}\text { Early } \\
\text { adversity }\end{array}$ & $\begin{array}{l}\text { Psychological } \\
\text { resources }\end{array}$ \\
\hline \multicolumn{5}{|l|}{ Major life events } \\
\hline Daily stress & $.28 *$ & & & \\
\hline Early adversity & $.39 *$ & $.28 \dagger$ & & \\
\hline Psychological resources & $-.33 \dagger$ & $-.33 \dagger$ & $-.49 *$ & \\
\hline Cortisol: baseline & -.01 & -.06 & -.10 & .11 \\
\hline Cortisol: post-TSST & -.04 & -.08 & $-.28 \dagger$ & .11 \\
\hline Cortisol: $+30 \mathrm{~min}$ & $-.20 \S$ & $-.20 \S$ & $-.28 \dagger$ & .08 \\
\hline Cortisol: $+45 \mathrm{~min}$ & $-.19 \S$ & -.18 & $-.31 \dagger$ & .13 \\
\hline Cortisol: $+60 \mathrm{~min}$ & -.17 & -.18 & $-.26 \neq$ & .15 \\
\hline Cortisol +90 min & -.10 & -.08 & $-.21 \neq$ & .16 \\
\hline IL-6: baseline & -.01 & -.14 & .01 & .05 \\
\hline IL-6: +30 min & -.02 & -.12 & .002 & -.01 \\
\hline IL-6: +45 min & -.02 & -.14 & -.03 & -.003 \\
\hline IL-6: +90 min & .03 & -.12 & -.02 & -.02 \\
\hline
\end{tabular}

Note: ${ }^{*} p<.001 ; \dagger p<.01 ; \ddagger p=.05 ; \S p<.063-.072$.

tion of stressor days $(p=.624)$ and psychological resources $(p=.990)$ were not related to cortisol levels at baseline (Table 3, column 3). In addition, psychological resources were not associated with cortisol reactivity to the TSST (linear: $p=.424$; quadratic: $p=.286$ ). However, there was a significant interaction between daily interpersonal stress and time (linear: $p=.017$; quadratic: $p=.011$ ). Adolescents who experienced more interpersonal stress in their daily lives had smaller cortisol responses (linear: $b(S E)=.19(.06), p=$ .001 ; quadratic: $b(S E)=-.04(.01), p<.001)$ compared with their peers who experienced less interpersonal stress in their everyday lives (linear: $b(S E)=.37(.04), p<.001$; quadratic: $b(S E)=-.07(.01), p<.001)$.

Variation in cortisol responses associated with daily interpersonal stress were further modulated by psychological resources, as reflected in the significant 3-way interaction among daily interpersonal stress, psychological resources, and time (linear: $p<.015$; quadratic: $p=.070$; Table 3, column 4). Tests of simple interactions indicated that daily interpersonal stress was associated with cortisol responses at lower levels of psychological resources (linear: $b(S E)=-.60(.22)$, $p=.006$; quadratic: $b(S E)=.09(.04), p=.020)$, but not at higher levels of psychological resources (linear: $b(S E)=-.07(.25), p=.778$; quadratic: $b(S E)=.04(.04)$, $p=.342$ ). Visualization of the simple interaction effects revealed a similar pattern as that depicted in Figure 1.

We also examined whether summing the number of daily stressors across days yielded similar findings given that the cumulative exposure to stress across days might be distinct from the proportion of stressor days. These two measures of daily stress were highly correlated $(r=.89, p<.001)$. Similar to proportion of stressor days, cumulative stress exposure modulated cortisol responses to the TSST (linear: $b(S E)=$ -.01(.01), $p=.028$; quadratic: $b(S E)=.002(.001), p=$ .027). Adolescents who reported a greater number of stressors across days had smaller cortisol responses (linear: $b(S E)=$
$.23(.07), p<.001$; quadratic: $b(S E)=-.04(.01), p<.001)$ compared with those who reported a smaller number of stressors across days (linear: $b(S E)=.36(.04), p<.001$; quadratic: $b(S E)=-.07$ (.01), $p<.001)$. Contrasting findings for proportion of stressor days, however, there was no evidence that the variation in cortisol responses related to cumulative stress exposure across days was further modulated by psychological resources (linear: $b(S E)=.01(.01), p=$ .119 ; quadratic: $b(S E)=-.001(.001), p=.459)$.

Early adversity. Table 3 (column 5) shows that early adversity $(p=.099)$ and psychological resources $(p=.396)$ were not associated with baseline cortisol. Psychological resources were not associated with rate of change in cortisol (linear: $p=.095)$, but was associated with quadratic change ( $p=$ .036). However, simple slope analyses revealed similar quadratic change at both high and low levels of psychological resources (quadratic: all $b \mathrm{~s}(S E)=-.06(.01)$, all $p s<.001$ ).

Similar to major life events and daily interpersonal stress, early adversity also modulated cortisol responses to the TSST (linear: $p=.002$; quadratic: $p<.001$ ). Cortisol responses were smaller among those reporting higher levels of early adversity (linear: $b(S E)=.20(.06), p=.001$; quadratic: $b(S E)=-.04(.01), p<.001)$ compared with cortisol responses among those reporting lower levels of early adversity (linear: $b(S E)=.36(.04), p<.001 ;$ quadratic: $b(S E)=-.07(.01)$, $p<.001)$.

There was a trend toward a three-way interaction among early adversity, psychological resources, and time (linear: $p=.073$; quadratic: $p=.310$; Table 3 , column 6). At low levels of psychological resources, early adversity was related to cortisol responses (linear: $b(S E)=-.26(.08), p=.001$; quadratic: $b(S E)$ $=.04(.01), p=.005)$. At high levels of psychological resources, early adversity was not related to cortisol responses (linear: $b(S E)$ $=-.07(.08), p=.406$; quadratic: $b(S E)=.03(.01), p=.072)$. 
Table 3. Results of models predicting cortisol from stress, psychological resources, and their interactions.

\begin{tabular}{|c|c|c|c|c|c|c|}
\hline & \multicolumn{2}{|c|}{ Major life events } & \multicolumn{2}{|c|}{ Daily interpersonal stress } & \multicolumn{2}{|c|}{ Early adversity } \\
\hline & $\begin{array}{c}\text { Model } 1 \\
b(S E)\end{array}$ & $\begin{array}{c}\text { Model } 2 \\
b(S E)\end{array}$ & $\begin{array}{c}\text { Model } 1 \\
b(S E)\end{array}$ & $\begin{array}{c}\text { Model } 2 \\
b(S E)\end{array}$ & $\begin{array}{c}\text { Model } 1 \\
b(S E)\end{array}$ & $\begin{array}{c}\text { Model } 2 \\
b(S E)\end{array}$ \\
\hline Intercept & $6.25(.92)^{*}$ & $6.31(.90)^{*}$ & $5.76(.94)^{*}$ & $5.99(.92)^{*}$ & $5.50(.88)^{*}$ & $5.67(.87)^{*}$ \\
\hline Gender & $-.17(.10) \S$ & $-.20(.10) \ddagger$ & $-.16(.10)$ & $-.18(.10) \S$ & $-.20(.09) \ddagger$ & $-.17(.09) \S$ \\
\hline Parent education & $-.004(.02)$ & $-.01(.02)$ & $-.003(.02)$ & $-.02(.02)$ & $-.01(.02)$ & $-.01(.02)$ \\
\hline Time of day & $-.28(.07)^{*}$ & $-.28(.07)^{*}$ & $-.24(.07)^{*}$ & $-.26(.07)^{*}$ & $-.22(.06)^{*}$ & $-.24(.06)^{*}$ \\
\hline Exercise & $.09(.04) \ddagger$ & $.09(.04) \ddagger$ & $.09(.04) \ddagger$ & $.09(.04) \ddagger$ & $.11(.04) \ddagger$ & $.12(.04) \dagger$ \\
\hline Smoking & $.23(.18)$ & $.23(.17)$ & $.20(.16)$ & $.22(.17)$ & $.27(.17)$ & $.23(.17)$ \\
\hline Oral contraceptives & $.08(.11)$ & $.13(.12)$ & $.0002(.11)$ & $.04(.11)$ & $-.05(.10)$ & $-.07(.10)$ \\
\hline Time & $.27(.03)^{*}$ & $.31(.03)^{*}$ & $.27(.03)^{*}$ & $.27(.03)^{*}$ & $.27(.03)^{*}$ & $.29(.03)^{*}$ \\
\hline Time $^{2}$ & $-.06(.01)^{*}$ & $-.06(.01)^{*}$ & $-.06(.01)^{*}$ & $-.06(.01)^{*}$ & $-.06(.004)^{*}$ & $-.06(.01)^{*}$ \\
\hline Stress & $-.02(.03)$ & $-.02(.03)$ & $-.15(.31)$ & $-.19(.31)$ & $-.19(.12)$ & $-.20(.12)$ \\
\hline Stress $\times$ time & $-.04(.01) \dagger$ & $-.04(.01) \dagger$ & $-.34(.14) \ddagger$ & $-.29(.14) \ddagger$ & $-.17(.05) \dagger$ & $-.16(.05) \dagger$ \\
\hline Stress $\times$ time $^{2}$ & $.01(.003) \dagger$ & $.01(.003) \dagger$ & $.06(.03) \ddagger$ & $.06(.03) \ddagger$ & $.03(.01)^{*}$ & $.03(.01) \dagger$ \\
\hline Psychological resources & $.01(.09)$ & $.02(.09)$ & $.001(.09)$ & $-.001(.09)$ & $-.08(.09)$ & $-.08(.10)$ \\
\hline Psychological resources $\times$ time & $-.04(.04)$ & $-.06(.04)$ & $-.03(.04)$ & $-.06(.04)$ & $-.07(.04)$ & $-.09(.04) \ddagger$ \\
\hline Psychological resources $\times$ time $^{2}$ & $.01(.01)$ & $.01(.01) \S$ & $.01(.01)$ & $.01(.01)$ & $.02(.01) \ddagger$ & $.02(.01) \ddagger$ \\
\hline Stress $\times$ psychological resources & & $-.04(.04)$ & & $-.05(.37)$ & & $-.03(.10)$ \\
\hline Stress $\times$ psychological resources $\times$ time & & $.07(.02)^{*}$ & & $.41(.17) \ddagger$ & & $.08(.05) \S$ \\
\hline Stress $\times$ psychological resources $\times$ time $^{2}$ & & $-.01(.003)^{*}$ & & $-.05(.03) \S$ & & $-.01(.01)$ \\
\hline
\end{tabular}

Note: $* p \leq .001 ; \dagger p .01 ; \neq p \leq .05 ; \S p=.058-.075$.

Gender was coded as $0=$ male and $1=$ female; ethnicity was coded as $0=$ European American and $1=$ Latino.

Visualization of the simple interaction effects revealed a similar pattern as that depicted in Figure 1.

\section{Inflammatory reactivity}

Major life events. As shown in Table 4 (column 1), neither major life events nor psychological resources were associated with baseline levels of IL-6 (major life events: $p=$ .812 ; psychological resources: $p=.332$ ) and IL-6 reactivity (major life events: $p=.669$; psychological resources: $p=$ .609). There was also no major life events by psychological

(a)

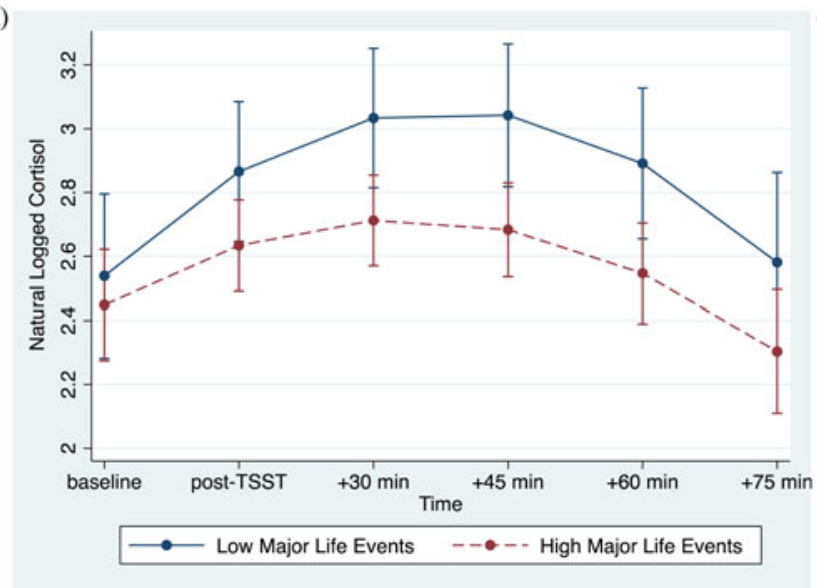

resources interaction effect on IL-6 reactivity $(p=.098$; Table 4, column 2).

Daily interpersonal stress. Table 4 also shows that daily interpersonal stress operationalized as proportion of stressor days and psychological resources were not related to IL-6 at baseline (daily stress: $p=.176$; psychological resources: $p=.452$ ) and in response to the TSST (daily stress: $p=.869$; psychological resources: $p=.408$ ). Daily interpersonal stress and psychological resources also did not interact to influence IL-6 reactivity ( $p=$ .261). The cumulative number of stressors across the days sim-

(b)

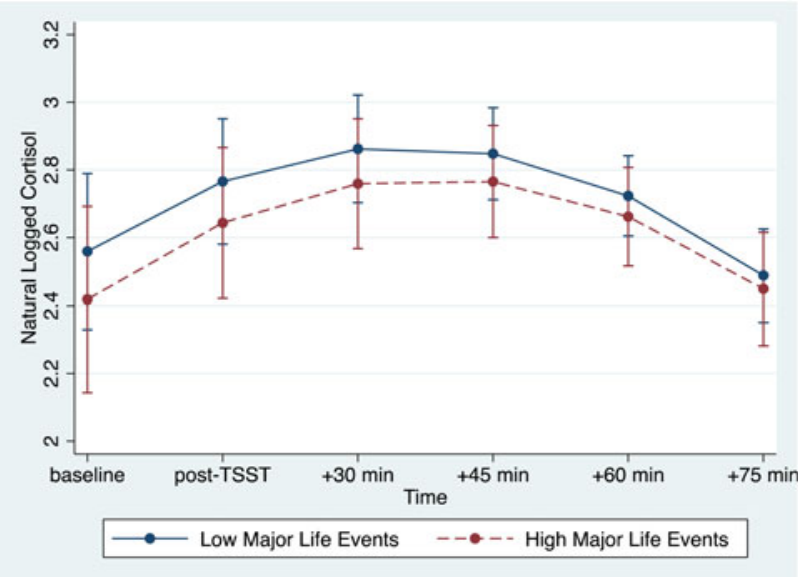

Figure 1. (Color online) (a) At lower levels of psychological resources, major life events are associated with decreased cortisol reactivity. (b) At higher levels of psychological resources, major life events are not associated with cortisol reactivity. Error bars reflect $95 \%$ confidence intervals. 
Table 4. Results of models predicting IL-6 from stress, psychological resources, and their interactions

\begin{tabular}{|c|c|c|c|c|c|c|}
\hline & \multicolumn{2}{|c|}{ Major life events } & \multicolumn{2}{|c|}{ Daily interpersonal stress } & \multicolumn{2}{|c|}{ Early adversity } \\
\hline & $\begin{array}{c}\text { Model } 1 \\
b(S E)\end{array}$ & $\begin{array}{c}\text { Model } 2 \\
b(S E)\end{array}$ & $\begin{array}{c}\text { Model } 1 \\
b(S E)\end{array}$ & $\begin{array}{c}\text { Model } 2 \\
b(S E)\end{array}$ & $\begin{array}{c}\text { Model } 1 \\
b(S E)\end{array}$ & $\begin{array}{c}\text { Model } 2 \\
b(S E)\end{array}$ \\
\hline Intercept & $-.51(.12)^{*}$ & $-.50(.12)^{*}$ & $-.50(.12)^{*}$ & $-.49(.12)^{*}$ & $-.49(.12)^{*}$ & $-.51(.12)^{*}$ \\
\hline Age & $-.02(.11)$ & $-.001(.11)$ & $-.04(.11)$ & $-.02(.11)$ & $-.002(.11)$ & $.001(.11)$ \\
\hline Gender & $.77(.11)^{*}$ & $.76(.11)^{*}$ & $.74(.11)^{*}$ & $.74(.11)^{*}$ & $.73(.11)^{*}$ & $.73(.11)^{*}$ \\
\hline Ethnicity & $.21(.12) \dagger$ & $.21(.12) \dagger$ & $.22(.12) \dagger$ & $.22(.12) \dagger$ & $.22(.12) \dagger$ & $.22(.12) \dagger$ \\
\hline Parent education & $-.02(.03)$ & $-.02(.03)$ & $-.03(.03)$ & $-.03(.03)$ & $-.02(.03)$ & $-.02(.03)$ \\
\hline Waist circumference & $.02(.004)^{*}$ & $.02(.004)^{*}$ & $.02(.004)^{*}$ & $.02(.004) *$ & $.02(.004) *$ & $.02(.004) *$ \\
\hline Time & $.12(.01)^{*}$ & $.12(.02)^{*}$ & $.11(.01)^{*}$ & $.11(.01)^{*}$ & $.12(.01)^{*}$ & $.12(.02)^{*}$ \\
\hline Stress & $-.03(.03)$ & $-.03(.03)$ & $-.37(.29)$ & $-.37(.29)$ & $-.09(.12)$ & $-.10(.12)$ \\
\hline Stress $\times$ time & $.003(.01)$ & $.003(.01)$ & $-.01(.07)$ & $-.001(.07)$ & $-.03(.03)$ & $-.03(.03)$ \\
\hline Psychological resources & $.08(.08)$ & $.08(.08)$ & $.06(.08)$ & $.05(.08)$ & $.06(.09)$ & $.07(.09)$ \\
\hline Psychological resources $\times$ time & $-.01(.02)$ & $-.02(.02)$ & $-.02(.02)$ & $-.02(.02)$ & $-.03(.02)$ & $-.03(.02)$ \\
\hline $\begin{array}{l}\text { Stress } \times \text { psychological } \\
\text { resources }\end{array}$ & & $-.003(.04)$ & & $.16(.34)$ & & $-.06(.09)$ \\
\hline $\begin{array}{l}\text { Stress } \times \text { psychological } \\
\text { resources } \times \text { time }\end{array}$ & & $.02(.01)$ & & $.09(.08)$ & & $.03(.02)$ \\
\hline
\end{tabular}

Note: $* p .001 ; \dagger p=.067-.083$. Gender was coded as $0=$ male and $1=$ female; ethnicity was coded as $0=$ European American and $1=$ Latino.

ilarly did not modulate IL-6 responses $(b(S E)=-.001(.003)$, $p=.619)$. This association was also not further modulated by psychological resources $(b(S E)=.003(.003), p=.306)$.

Early adversity. Again as shown in Table 4, early adversity and psychological resources were not associated with baseline IL-6 (early adversity: $p=.455$; psychological resources: $p=.494$ ) and IL-6 reactivity (early adversity: $p=.283$; psychological resources: $p=.248$ ). There was also no interaction effect between early adversity and psychological resources on inflammatory reactivity $(p=.10)$.

\section{Sensitivity analyses}

We tested whether higher psychological resources may be a proxy for better overall mental health by statistically adjusting for depressive symptoms and by testing whether depressive symptoms interacted with the various stressors to predict HPA reactivity. Results remained the same when including depressive symptoms as a covariate. There was also no evidence that daily interpersonal stress or early adversity interacted with depressive symptoms to influence cortisol responses (linear terms: all $p \mathrm{~s}=.644-.796$; quadratic terms: all $p \mathrm{~s}=.564-.885$ ). Depressive symptoms did, however, interact with major life events to predict cortisol responses (linear term: $b(S E)=-.004(.001), p=.003$; quadratic term: $b(S E)=.001(.0003), p=.023)$. Major life events were related to cortisol reactivity only among those with higher depressive symptoms $(\mathrm{n}=21$; linear term: $b(S E)=$ $-.06(.03), p=.019$; quadratic term: $b(S E)=.01(.005)$, $p=.074)$, but not among those with lower depressive symptoms $(\mathrm{n}=33$; linear term: $b(S E)=.01(.03), p=.803$; quadratic term: $b(S E)=-.002(.005), p=.643)$.

\section{Exploratory analyses}

Compared with European-Americans, Latinos face higher rates of poverty and socioeconomic and racial discrimination and have different family values, which may lead to differential effects of stress and psychological resources on biological responsivity. Therefore, we examined whether ethnicity moderated the effects of stress and the effects of the stress by psychological resources interactions on cortisol and IL-6 responses. Overall there was no evidence that stress associations with cortisol (linear: all ps $>.352$; quadratic: all $p$ s $>$ .155 ) and IL-6 (all ps $>$.110) responses were different across ethnicity. The only exception to this pattern of findings was the association between early adversity and cortisol responses (linear term: $b(S E)=-.31(.12), p=.009$; quadratic term: $b(S E)=.06(.02), p=.003)$. Early adversity was associated with decreased cortisol responses among Latinos (linear term: $b(S E)=-.25(.07), p<.001$; quadratic term: $b(S E)=$ $.05(.01), p<.001)$, but not among European-Americans (linear term: $b(S E)=.01(.09), p=.947$; quadratic term: $b(S E)=-.01(.01), p=.699)$. There was no evidence of ethnic differences in stress associations with cortisol (linear: all $p \mathrm{~s}>$.590; quadratic: all $p \mathrm{~s}>.255$ ) and IL-6 (all $p \mathrm{~s}>$ .065 ) responses moderated by psychological resources.

\section{Discussion}

The present study aimed to deepen our understanding of factors that may protect against the negative biological effects of psychosocial stress during adolescence, a developmental period important to the establishment of future adult health. Consistent with work on childhood and adolescent stress and HPA axis responses to subsequent acute stress (e.g., 
Cărnuţă et al., 2015; Carpenter et al., 2007; Elzinga et al., 2008; Kraft \& Luecken, 2009), we found that experiences of various stressors, including major life events, daily interpersonal stress, and early adversity, were associated with smaller cortisol responses to an acute laboratory-based stressor. Individual psychological resources moderated the links from major life events and daily stress to cortisol reactivity, such that they were evident only among adolescents who reported lower levels of psychological resources. By comparison, these stress-cortisol reactivity associations were not apparent among those reporting higher levels of psychological resources. These findings were specific to the HPA axis and were not evident for inflammatory processes.

The present findings converge with work showing that among socioeconomically disadvantaged youth, positive reappraisal tendencies, and finding meaning in life were associated with reduced risk of poor health-related outcomes, such as obesity and cardiovascular risk (Chen et al., 2013, 2015; Kallem et al., 2013). We extend this work by demonstrating that individual psychological resources may also protect young individuals from the effects of other stressors, including major life events, daily interpersonal stress, and to some extent early adversity, on reduced HPA responses to acute stress, which is thought to be one key mechanism linking stress to health and psychopathology (Ehrlich et al., 2016; Heim \& Binder, 2012).

The current findings raise the question of how psychological resources may counter the effects of chronic or repeated stress on HPA axis reactivity to subsequent acute stress. One explanation is that psychological resources foster effective coping strategies (Taylor \& Broffman, 2011; Taylor \& Stanton, 2007). Having higher levels of optimism, self-esteem, self-mastery, and a tendency to positively reappraise negative or threatening situations likely biases one towards regulation of stress-evoked negative emotions, active problem-solving, and/or seeking support or other resources, over maladaptive ways of coping, such as rumination. In the face of major life events or repeated daily stress, these coping strategies may attenuate HPA reactivity and/or facilitate quicker recovery. To the extent that hypocortisolism results after extended periods of high levels of cortisol as a counterregulatory mechanism (Fries et al., 2005; Miller et al., 2007), attenuated reactivity to and/or quicker recovery from previous stress may reduce the amount of overall exposure to cortisol and prevent or delay hypocortisolism from emerging.

Psychological resources seemed to have stronger protective effects for major life events and daily stress relative to early adversity. Whereas significant interactions with psychological resources emerged for major life events and daily stress, there was only a marginally significant interaction between early adversity and psychological resources on linear cortisol changes, and there was no interaction for quadratic cortisol changes. Why we observed this pattern is not entirely clear, but may have to do with temporal distance between exposure to the different stressors and the assessment of cortisol responses. In the current study, major life events tapped into stressful events within the last year and daily stress assessed the everyday interpersonal in participants' current lives. By contrast, early adversity assessed participants' family climate from ages 5 to 15. Given the longer period between early adversity and assessment of HPA reactivity, the effects of early adversity may have had more sufficient time to "get under the skin" and solidify. As such, psychological resources may be particularly less effective for more temporally distal stressors relatively to more temporally proximal severe stressors. Of course, this remains speculative, and requires empirical examination.

One caveat to the observed pattern of findings is that there was some evidence that psychological resources per se did not buffer the effects of major life events on cortisol responses. Psychological resources and depressive symptoms were correlated fairly strongly $\left(\mathrm{r} \frac{1}{4}-.60\right)$, and major life events interacted with depressive symptoms, such that major life events were related to cortisol responses only among those with higher depressive symptoms, but not among individuals with lower depressive symptoms. It may be that for the effects of major life events, psychological resources served as a proxy for overall adjustment, and lower mental health may be the important moderator that accentuates relations between major life events and HPA axis functioning. Psychological resources, on the other hand, may be effective in counteracting the adverse health-related effects not only of socioeconomic disadvantage, as shown in previous studies (Chen et al., 2013; Chen et al., 2015; Kallem et al., 2013), but also of other chronic stressors such as more mundane daily stressors that may accumulate over time.

Interestingly, exploratory analyses revealed ethnic differences in the associations between early adversity and cortisol responses, but not in the buffering role of psychological resources. Specifically, the association between early adversity and cortisol reactivity was evident only in Latino adolescents, but not in their European-American counterparts. These findings may reflect ethnic differences in family values. Our measures of early adversity assessed overall family environment, and compared with European-American families, Latino families are characterized by higher levels of familism, or the view that the family constitutes the self and is the primary source of support; family duties, interconnectedness and unity among family members, and family needs rather than individual needs are also emphasized (Fuligni et al., 1999; Sabogal et al., 1987). As such, early family-related stress may be more distressing for Latino adolescents. We found no ethnic differences in the protective role of psychological resources, which might suggest that psychological resources do not operate as a protective factor for Latino youth exposed to a harsh family climate. However, the current sample size may be a limiting factor. Future work should further probe psychological resources as a possible protective factor, particularly for Latino youth experiencing high levels of family-related stress.

Findings for stress and its interaction with psychological resources were specific to the HPA axis and not observed for inflammatory reactivity. At first, this may seem somewhat 
surprising given that the HPA axis regulates inflammatory activity (Irwin \& Cole, 2011; Rohleder, 2014). In particular, cortisol downregulates the production of cytokines when bound to its corresponding receptors in immune cells; as such, decreased cortisol reactivity might be expected to result in increases in circulating levels of IL-6 among those with higher levels of stress and lower levels of psychological resources. However, for cortisol to bind to its receptor in immune cells, cortisol must be unbound to carrier proteins. Yet, only a small fraction of cortisol (approximately 10\%) remains unbound and biologically active (El-Farhan, Rees, \& Evans, 2017). Furthermore, before modifying other biological systems, including the immune system, unbounded, free cortisol, must avoid being excreted and converted to its inactive form by counterregulatory mechanisms (Ehrlich et al., 2016; Miller et al., 2009). Once bound to its receptors, it must translocate to the nucleus of the cell, where it can then exert its effects. Measures of salivary cortisol, as used in the present study, do not offer any insight into these processes, and therefore the downstream effects of the smaller cortisol responses on inflammatory processes in adolescents with higher levels of stress and lower psychological resources cannot be determined in the present study.

That we observed no stress and IL- 6 associations or moderation by psychological resources seems to diverge from prior studies showing significant interactions between socioeconomic status and psychological resources on inflammatory processes (Chen et al., 2015; Elliot \& Chapman, 2016). However, these studies examined production of inflammatory cytokines in response to a bacterial stimulus in youth and circulating markers of systemic inflammation under tonic conditions in midlife adults. In the present study, we focused on circulating IL-6 in response to an acute psychosocial stressor in late adolescents. The lack of findings for IL-6 reactivity may have to do with the fact that systemic inflammation remains low in earlier life stages, whereas the HPA axis is known to be highly sensitive to the environment across the lifespan, even early in life when physical health is relatively intact (Gunnar \& Quevedo, 2007; Hostinar, Sullivan, \& Gunnar, 2014). As such, there may be delayed effects of stress on circulating markers of inflammation, and links may emerge in later in life. Consistent with this notion, associations between stress and circulating markers of inflammation are more consistently observed in adults compared with youth (Baumeister et al., 2016; Coelho et al., 2014; Slopen et al., 2012). That circulating inflammatory cytokines

\section{References}

American Psychological Association. (2014). Stress in America: Are teens adopting adults' stress habits. Stress in America Surveys. Retrieved from June 13, 2018, from http://www/apa.org/news/press/releases/stress/2013/ stress-report.pdf

Baumeister, D., Akhtar, R., Ciufolini, S., Pariante, C. M., \& Mondelli, V. (2016). Childhood trauma and adulthood inflammation: a meta-analysis of peripheral C-reactive protein, interleukin-6 and tumour necrosis factor- $\alpha$. Molecular Psychiatry, 21, 642-649. https://doi.org/10.1038/mp.2015.67

Black, P. H. (2003). The inflammatory response is an integral part of the stress response: Implications for atherosclerosis, insulin resistance, type stem from both immune and nonimmune sources, such as adipocytes (Black, 2003), may also make it difficult to detect associations among stress, psychological resources, and inflammatory reactivity in young individuals. To the extent that stress biases immune cells specifically toward a pro-inflammatory phenotype (Miller et al., 2011) and that psychological resources counteract the impact of stress (as described previously), effects in young persons may be better detected when stimulating immune cells, as in the study by Chen et al. (2015).

The current investigation was not without limitations. First, the observational nature of the study precludes any conclusion about causal relations and makes alternative explanations plausible. Although we adjusted for potential confounds and considered depressive symptoms as an alternative explanation, other unmeasured factors associated with stress and HPA axis functioning may have contributed to the observed findings. Second, given the one-time assessment of HPA axis reactivity to stress, we were unable to determine whether the effects of the various stressors on cortisol reactivity and the attenuation of these associations by psychological resources persist across time. As development continues, later experiences may alter the health trajectories that early experiences initially set in motion (Chiang, Chen, \& Miller, 2018; Gouin, Caldwell, Woods, \& Malarkey, 2017), making it important for future longitudinal studies to elucidate whether the current findings persist across time. Third, the clinical relevance of the study findings cannot be determined. We did not measure any physical health outcomes, and the clinical significance of the magnitude of cortisol decreases we observed remain unknown. Last, participants were European- and Latin-Americans from the Los Angeles area and of a narrow age range; thus, more work is needed to determine generalizability of our findings.

Despite these limitations, the current study contributes to previous literature. It builds on prior research on psychological resources by extending findings of the protective role of psychological resources to an adolescent sample. It extends work on adolescent stress biology by highlighting psychological resources as potential protective factors that may mitigate the association between stress and dampened cortisol reactivity. Results raise the possibility that intervention programs aimed at enhancing psychological resources among young individuals may ultimately help counteract the effects of certain stressors on HPA axis functioning, though the long-term health implications remain unclear.

II diabetes and metabolic syndrome X. Brain, Behavior, and Immunity, $17,350-364$

Blakemore, S. J., \& Mills, K. L. (2014). Is adolescence a sensitive period for sociocultural processing? Annual Review of Psychology, 65, 187-207.

Boylan, J. M., Jennings, J. R., \& Matthews, K. A. (2016). Childhood socioeconomic status and cardiovascular reactivity and recovery among Black and White men: Mitigating effects of psychological resources. Health Psychology, 35, 957-966.

Brody, G. H., Yu, T., \& Beach, S. R. H. (2016). Resilience to adversity and the early origins of disease. Development and 
Psychopathology, 28, 1347-1365. https://doi.org/10.1017/ S0954579416000894

Brown, D. W., Anda, R. F., Tiemeier, H., Felitti, V. J., Edwards, V. J., Croft, J. B., \& Giles, W. H. (2009). Adverse childhood experiences and the risk of premature mortality. American Journal of Preventive Medicine, 37, 389-396.

Brydon, L., \& Steptoe, A. (2005). Stress-induced increases in interleukin-6 and fibrinogen predict ambulatory blood pressure at 3-year follow-up. Journal of Hypertension, 23, 1001-1007.

Bunea, I. M., Szentágotai-Tătar, A., \& Miu, A. C. (2017). Early-life adversity and cortisol response to social stress: A meta-analysis. Translational Psychiatry, 7, 1274.

Cărnuţă, M., Crişan, L. G., Vulturar, R., Opre, A., \& Miu, A. C. (2015). Emotional non-acceptance links early life stress and blunted cortisol reactivity to social threat. Psychoneuroendocrinology, 51, 176-187.

Carpenter, L. L., Carvalho, J. P., Tyrka, A. R., Wier, L. M., Mello, A. F., Mello, M. F., . . Price, L. H. (2007). Decreased adrenocorticotropic hormone and cortisol responses to stress in healthy adults reporting significant childhood maltreatment. Biological Psychiatry, 62, 1080-1087.

Carpenter, L. L., Shattuck, T. T., Tyrka, A. R., Geracioti, T. D., \& Price, L. H. (2011). Effect of childhood physical abuse on cortisol stress response. Psychopharmacology, 214, 367-375.

Carroll, D., Bibbey, A., Roseboom, T. J., Phillips, A. C., Ginty, A. T., \& Rooij, S. R. (2012). Forced expiratory volume is associated with cardiovascular and cortisol reactions to acute psychological stress. Psychophysiology, 49, 866-872.

Carroll, J. E., Gruenewald, T. L., Taylor, S. E., Janicki-Deverts, D., Matthews, K. A., \& Seeman, T. E. (2013). Childhood abuse, parental warmth, and adult multisystem biological risk in the Coronary Artery Risk Development in Young Adults study. Proceedings of the National Academy of Sciences, 110, 17149-17153.

Carver, C. S., Scheier, M. F., \& Segerstrom, S. C. (2010). Optimism. Clinical Psychology Review, 30, 879-889.

Chen, E., Lee, W. K., Cavey, L., \& Ho, A. (2013). Role models and the psychological characteristics that buffer low-socioeconomic-status youth from cardiovascular risk. Child Development, 84, 1241-1252.

Chen, E., McLean, K. C., \& Miller, G. E. (2015). Shift-and-persist strategies: Associations with socioeconomic status and the regulation of inflammation among adolescents and their parents. Psychosomatic Medicine, 77, 371-382.

Chen, E., \& Miller, G. E. (2013). Socioeconomic status and health: Mediating and moderating factors. Annual Review of Clinical Psychology, 9, 723-749.

Chen, E., Miller, G. E., Kobor, M. S., \& Cole, S. W. (2011). Maternal warmth buffers the effects of low early-life socioeconomic status on pro-inflammatory signaling in adulthood. Molecular Psychiatry, 16, 729-737. 3

Chiang, J. J., Bower, J. E., Irwin, M. R., Taylor, S. E., \& Fuligni, A. J. (2017). Adiposity moderates links from early adversity and depressive symptoms to inflammatory reactivity to acute stress during late adolescence. Brain, Behavior, and Immunity, 66, 146-155.

Chiang, J. J., Chen, E., \& Miller, G. E. (2018). Midlife self-reported social support as a buffer against premature mortality risks associated with childhood abuse. Nature Human Behaviour, 2, 261-268.

Chiang, J. J., Eisenberger, N. I., Seeman, T. E., \& Taylor, S. E. (2012). Negative and competitive social interactions are related to heightened proinflammatory cytokine activity. Proceedings of the National Academy of Sciences, 109(6), 1878-1882.

Chiang, J. J., Taylor, S. E., \& Bower, J. E. (2015). Early adversity, neural development, and inflammation. Developmental Psychobiology, 57, 887-907.

Chiang, J. J., Tsai, K. M., Park, H., Bower, J. E., Almeida, D. M., Dahl, R. E., ... Fuligni, A. J. (2016). Daily family stress and HPA axis functioning during adolescence: The moderating role of sleep. Psychoneuroendocrinology, 71, 43-53.

Choy, E. (2012). Understanding the dynamics: Pathways involved in the pathogenesis of rheumatoid arthritis. Rheumatology, 51, v3-v11.

Chung, G. H., Flook, L., \& Fuligni, A. J. (2009). Daily family conflict and emotional distress among adolescents from Latin American, Asian, and European backgrounds. Developmental Psychology, 45, 1406-1415.

Coelho, R., Viola, T. W., Walss-Bass, C., Brietzke, E., \& Grassi-Oliveira, R. (2014). Childhood maltreatment and inflammatory markers: A systematic review. Acta Psychiatrica Scandinavica, 129, 180-192.

Cohen, S., Doyle, W. J., Turner, R. B., Alper, C. M., \& Skoner, D. P. (2004). Childhood socioeconomic status and host resistance to infectious illness in adulthood. Psychosomatic Medicine, 66, 553-558.
Conger, R. D., Wallace, L. E., Sun, Y., Simons, R. L., McLoyd, V. C., \& Brody, G. H. (2002). Economic pressure in African American families: A replication and extension of the family stress model. Developmental Psychology, 38, 179-193.

de Rooij, S. R. (2013). Blunted cardiovascular and cortisol reactivity to acute psychological stress: A summary of results from the Dutch Famine Birth Cohort Study. International Journal of Psychophysiology, 90, 21-27.

Del Giudice, M., Ellis, B. J., \& Shirtcliff, E. A. (2011). The adaptive calibration model of stress responsivity. Neuroscience \& Biobehavioral Reviews, 35, 1562-1592.

DeLongis, A., Folkman, S., \& Lazarus, R. S. (1988). The impact of daily stress on health and mood: psychological and social resources as mediators. Journal of Personality and Social Psychology, 54, 486.

Demakakos, P., Pillas, D., Marmot, M., \& Steptoe, A. (2016). Parenting style in childhood and mortality risk at older ages: A longitudinal cohort study. The British Journal of Psychiatry, 209, 135-141.

DeSantis, A. S., Adam, E. K., Doane, L. D., Mineka, S., Zinbarg, R. E., \& Craske, M. G. (2007). Racial/ethnic differences in cortisol diurnal rhythms in a community sample of adolescents. Journal of Adolescent Health, 41, 3-13.

Dickerson, S. S., \& Kemeny, M. E. (2004). Acute stressors and cortisol responses: A theoretical integration and synthesis of laboratory research. Psychological Bulletin, 130, 355-391.

Dietz, L. J., Stoyak, S., Melhem, N., Porta, G., Matthews, K. A., Payne, M. W., \& Brent, D. A. (2013). Cortisol response to social stress in parentally bereaved youth. Biological Psychiatry, 73, 379-387.

Dowd, J. B., Simanek, A. M., \& Aiello, A. E. (2009). Socio-economic status, cortisol and allostatic load: A review of the literature. International Journal of Epidemiology, 38, 1297-1309.

Ehrlich, K. B., Miller, G. E., \& Chen, E. (2016). Childhood adversity and adult physical health Developmental Psychopathology (Vol. 4 , pp. 1-42). Hoboken, NJ: Wiley.

El-Farhan, N., Rees, D. A., \& Evans, C. (2017). Measuring cortisol in serum, urine and saliva-Are our assays good enough? Annals of Clinical Biochemistry, 54, 308-322.

Elinav, E., Nowarski, R., Thaiss, C. A., Hu, B., Jin, C., \& Flavell, R. A. (2013). Inflammation-induced cancer: Crosstalk between tumours, immune cells and microorganisms. Nature Reviews. Cancer, 13, 759-771

Elliot, A. J., \& Chapman, B. P. (2016). Socioeconomic status, psychological resources, and inflammatory markers: Results from the MIDUS study. Health Psychology, 35, 1205-1213.

Elzinga, B. M., Roelofs, K., Tollenaar, M. S., Bakvis, P., van Pelt, J., \& Spinhoven, P. (2008). Diminished cortisol responses to psychosocial stress associated with lifetime adverse events: A study among healthy young subjects. Psychoneuroendocrinology, 33, 227-237.

Engert, V., Efanov, S. I., Dedovic, K., Duchesne, A., Dagher, A., \& Pruessner, J. C. (2010). Perceived early-life maternal care and the cortisol response to repeated psychosocial stress. Journal of Psychiatry \& Neuroscience, 35, 370-377.

Fries, E., Hesse, J., Hellhammer, J., \& Hellhammer, D. H. (2005). A new view on hypocortisolism. Psychoneuroendocrinology, 30, 1010-1016.

Fuligni, A. J., Telzer, E. H., Bower, J., Cole, S. W., Kiang, L., \& Irwin, M. R. (2009). A preliminary study of daily interpersonal stress and C-reactive protein levels among adolescents from Latin American and European backgrounds. Psychosomatic Medicine, 71, 329-333.

Fuligni, A. J., Tseng, V., \& Lam, M. (1999). Attitudes toward family obligations among American adolescents with Asian, Latin American, and European backgrounds. Child Development, 70, 1030-1044.

Gallo, L. C., de los Monteros, K. E., \& Shivpuri, S. (2009). Socioeconomic status and health: What is the role of reserve capacity? Current Directions in Psychological Science, 18, 269-274.

Gouin, J. P., Caldwell, W., Woods, R., \& Malarkey, W. B. (2017). Resilience resources moderate the association of adverse childhood experiences with adulthood inflammation. Annals of Behavioral Medicine, 51, 782-786.

Greene, M. L., Way, N., \& Pahl, K. (2006). Trajectories of perceived adult and peer discrimination among Black, Latino, and Asian American adolescents: Patterns and psychological correlates. Developmental Psychology, 42, 218-236.

Gross, J. J., \& John, O. P. (2003). Individual differences in two emotion regulation processes: Implications for affect, relationships, and well-being. Journal of Personality and Social Psychology, 85, 348-362.

Grzywacz, J. G., Almeida, D. M., \& McDonald, D. A. (2002). Work-family spillover and daily reports of work and family stress in the adult labor force. Family Relations, 51(1), 28-36. 
Gunnar, M., \& Quevedo, K. (2007). The neurobiology of stress and development. Annual Review of Psychology, 58, 145-173.

Gunnar, M. R., Wewerka, S., Frenn, K., Long, J. D., \& Griggs, C. (2009). Developmental changes in hypothalamus-pituitary-adrenal activity over the transition to adolescence: Normative changes and associations with puberty. Development and Psychopathology, 21, 69-85.

Hammen, C. (1991). Generation of stress in the course of unipolar depression. Journal of Abnormal Psychology, 100, 555-561.

Heim, C., \& Binder, E. B. (2012). Current research trends in early life stress and depression: Review of human studies on sensitive periods, geneenvironment interactions, and epigenetics. Experimental Neurology, $233,102-111$.

Heim, C., Ehlert, U., \& Hellhammer, D. H. (2000). The potential role of hypocortisolism in the pathophysiology of stress-related bodily disorders. Psychoneuroendocrinology, 25, 1-35.

Hostinar, C. E., Sullivan, R. M., \& Gunnar, M. R. (2014). Psychobiological mechanisms underlying the social buffering of the hypothalamic-pituitary-adrenocortical axis: A review of animal models and human studies across development. Psychological Bulletin, 140, 256-282.

Irwin, M. R., \& Cole, S. W. (2011). Reciprocal regulation of the neural and innate immune systems. Nature Reviews Immunology, 11, 625-632.

Jacks, D. E., Sowash, J., Anning, J., Mcgloughlin, T., \& Andres, F. (2002). Effect of exercise at three exercise intensities on salivary cortisol. The Journal of Strength \& Conditioning Research, 16, 286-289.

Janusek, L. W., Tell, D., Gaylord-Harden, N., \& Mathews, H. L. (2017). Relationship of childhood adversity and neighborhood violence to a proinflammatory phenotype in emerging adult African American men: An epigenetic link. Brain, Behavior, and Immunity, 60, 126-135.

Kallem, S., Carroll-Scott, A., Rosenthal, L., Chen, E., Peters, S. M., McCaslin, C., \& Ickovics, J. R. (2013). Shift-and-persist: A protective factor for elevated BMI among low-socioeconomic-status children. Obesity, 21, $1759-1763$.

Kershaw, K. N., Brenes, G. A., Charles, L. E., Coday, M., Daviglus, M. L., Denburg, N. L., . . Tindle, H. A. (2014). Associations of stressful life events and social strain with incident cardiovascular disease in the Women's Health Initiative. Journal of the American Heart Association, 3, e000687.

Kirschbaum, C., Pirke, K. M., \& Hellhammer, D. H. (1993). The 'Trier Social Stress Test'-a tool for investigating psychobiological stress responses in a laboratory setting. Neuropsychobiology, 28, 76-81.

Kraft, A. J., \& Luecken, L. J. (2009). Childhood parental divorce and cortisol in young adulthood: Evidence for mediation by family income. Psychoneuroendocrinology, 34, 1363-1369.

Libby, P. (2006). Inflammation and cardiovascular disease mechanisms. The American Journal of Clinical Nutrition, 83, 456S-460S.

Loucks, E. B., Almeida, N. D., Taylor, S. E., \& Matthews, K. A. (2011). Childhood family psychosocial environment and coronary heart disease risk. Psychosomatic Medicine, 73, 563-571.

Lovallo, W. R. (2013). Early life adversity reduces stress reactivity and enhances impulsive behavior: Implications for health behaviors. International Journal of Psychophysiology, 90, 8-16.

Lovallo, W. R., Whitsett, T. L., al'Absi, M., Sung, B. H., Vincent, A. S., \& Wilson, M. F. (2005). Caffeine stimulation of cortisol secretion across the waking hours in relation to caffeine intake levels. Psychosomatic Medicine, 67, 734-739.

Luecken, L. J., \& Appelhans, B. M. (2006). Early parental loss and salivary cortisol in young adulthood: The moderating role of family environment. Development and Psychopathology, 18, 295-308.

Lundgren, O., Garvin, P., Jonasson, L., Andersson, G., \& Kristenson, M. (2015). Psychological resources are associated with reduced incidence of coronary heart disease. An 8-year follow-up of a communitybased Swedish sample. International Journal of Behavioral Medicine, $22,77-84$.

MacMillan, H. L., Georgiades, K., Duku, E. K., Shea, A., Steiner, M., Niec, A., . . . Vella, E. (2009). Cortisol response to stress in female youths exposed to childhood maltreatment: Results of the youth mood project. Biological Psychiatry, 66, 62-68.

Marsland, A. L., Walsh, C., Lockwood, K., \& John-Henderson, N. A. (2017). The effects of acute psychological stress on circulating and stimulated inflammatory markers: A systematic review and meta-analysis. Brain, Behavior, and Immunity, 64, 208-219.

McEwen, B. S., \& Seeman, T. (1999). Protective and damaging effects of mediators of stress: Elaborating and testing the concepts of allostasis and allostatic load. Annals of the New York Academy of Sciences, 896, 30-47.
Miller, G. E., \& Chen, E. (2010). Harsh family climate in early life presages the emergence of a proinflammatory phenotype in adolescence. Psychological Science, 21, 848-856.

Miller, G. E., Chen, E., Fok, A. K., Walker, H., Lim, A., Nicholls, E. F., . . Kobor, M. S. (2009). Low early-life social class leaves a biological residue manifested by decreased glucocorticoid and increased proinflammatory signaling. Proceedings of the National Academy of Sciences, 106, 14716-14721.

Miller, G. E., Chen, E., \& Parker, K. J. (2011). Psychological stress in childhood and susceptibility to the chronic diseases of aging: Moving toward a model of behavioral and biological mechanisms. Psychological Bulletin, 137, 959-997.

Miller, G. E., Chen, E., \& Zhou, E. S. (2007). If it goes up, must it come down? Chronic stress and the hypothalamic-pituitary-adrenocortical axis in humans. Psychological Bulletin, 133, 25-45.

Nishina, A., \& Juvonen, J. (2005). Daily reports of witnessing and experiencing peer harassment in middle school. Child Development, 76, 435-450.

O'Connor, M. F., Bower, J. E., Cho, H. J., Creswell, J. D., Dimitrov, S., Hamby, M. E., . . Sloan, E. K. (2009). To assess, to control, to exclude: effects of biobehavioral factors on circulating inflammatory markers. Brain, Behavior, and Immunity, 23, 887-897.

Pearlin, L. I., \& Schooler, C. (1978). The structure of coping. Journal of Health and Social Behavior, 19, 2-21.

Phillips, A. C., Carroll, D., Burns, V. E., \& Drayson, M. (2005). Neuroticism, cortisol reactivity, and antibody response to vaccination. Psychophysiology, 42, 232-238.

Pyykkönen, A. J., Räikkönen, K., Tuomi, T., Eriksson, J. G., Groop, L., \& Isomaa, B. (2010). Stressful life events and the metabolic syndrome. Diabetes Care, 33, 378-384.

Repetti, R. L., Robles, T. F., \& Reynolds, B. (2011). Allostatic processes in the family. Development and Psychopathology, 22, 921-938.

Repetti, R. L., Taylor, S. E., \& Seeman, T. E. (2002). Risky families: Family social environments and the mental and physical health of offspring. Psychological Bulletin, 128, 330-366.

Rohleder, N. (2014). Stimulation of systemic low-grade inflammation by psychosocial stress. Psychosomatic Medicine, 76, 181-189.

Rosenberg, M. (1965). Society and the adolescent self-image. Princeton, NJ: Princeton University Press.

Sabogal, F., Marín, G., Otero-Sabogal, R., Marín, B. V., \& Perez-Stable, E. J. (1987). Hispanic familism and acculturation: What changes and what doesn't? Hispanic Journal of Behavioral Sciences, 9, 397-412.

Scheier, M. F., Carver, C. S., \& Bridges, M. W. (1994). Distinguishing optimism from neuroticism (and trait anxiety, self-mastery, and self-esteem): A reevaluation of the Life Orientation Test. Journal of Personality and Social Psychology, 67, 1063-1078.

Sebastian, C., Viding, E., Williams, K. D., \& Blakemore, S. J. (2010). Social brain development and the affective consequences of ostracism in adolescence. Brain and Cognition, 72, 134-145.

Semega, J. L., Frontenot, K. R., Kollar, M. A., \& Bureau, U. S. C. (2017). Income and poverty in the United States: 2016. Washington DC: US Government Printing Office.

Sin, N. L., Graham-Engeland, J. E., Ong, A. D., \& Almeida, D. M. (2015) Affective reactivity to daily stressors is associated with elevated inflammation. Health Psychology, 34, 1154-1165.

Slavich, G. M., \& Irwin, M. R. (2014). From stress to inflammation and major depressive disorder: A social signal transduction theory of depression. Psychological Bulletin, 140, 774-815.

Slopen, N., Koenen, K. C., \& Kubzansky, L. D. (2012). Childhood adversity and immune and inflammatory biomarkers associated with cardiovascular risk in youth: A systematic review. Brain, Behavior, and Immunity, 26, 239-250.

Slopen, N., Kubzansky, L. D., McLaughlin, K. A., \& Koenen, K. C. (2013). Childhood adversity and inflammatory processes in youth: A prospective study. Psychoneuroendocrinology, 38, 188-200.

Somerville, L. H. (2013). The teenage brain: Sensitivity to social evaluation Current Directions in Psychological Science, 22, 121-127.

Spear, L. P. (2009). Heightened stress responsivity and emotional reactivity during pubertal maturation: Implications for psychopathology. Development and Psychopathology, 21, 87-97.

Stamatakis, K. A., Lynch, J. W., Everson, S. A., Raghunathan, T., Salonen, J. T., \& Kaplan, G. A. (2004). Self-esteem and mortality: prospective evidence from a population-based study. Annals of Epidemiology, 14, 58-65.

Stawski, R. S., Cichy, K. E., Piazza, J. R., \& Almeida, D. M. (2013). Associations among daily stressors and salivary cortisol: Findings from the 
National Study of Daily Experiences. Psychoneuroendocrinology, 38, 2654-2665.

Steptoe, A., Hamer, M., \& Chida, Y. (2007). The effects of acute psychological stress on circulating inflammatory factors in humans: A review and meta-analysis. Brain, Behavior, and Immunity, 21, 901-912.

Stone, A. A., Neale, J. M., Cox, D. S., Napoli, A., Valdimarsdottir, H., \& Kennedy-Moore, E. (1994). Daily events are associated with a secretory immune response to an oral antigen in men. Health Psychology, $13,440-446$.

Stroud, C. B., Chen, F. R., Doane, L. D., \& Granger, D. A. (2016). Individual differences in early adolescents' latent trait cortisol (LTC): Relation to early adversity. Developmental Psychobiology, 58, 700-713.

Stroud, L. R., Foster, E., Papandonatos, G. D., Handwerger, K., Granger, D. A., Kivlighan, K. T., \& Niaura, R. (2009). Stress response and the adolescent transition: Performance versus peer rejection stressors. Development and Psychopathology, 21, 47-68.

Surtees, P. G., Wainwright, N. W. J., Luben, R., Khaw, K. T., \& Day, N. E. (2006). Mastery, sense of coherence, and mortality: Evidence of independent associations from the EPIC-Norfolk Prospective Cohort Study. Health Psychology, 25, 102-110.

Syed, S. A., \& Nemeroff, C. B. (2017). Early life stress, mood, and anxiety disorders. Chronic Stress, 1, 1-16.
Taylor, S. E., \& Broffman, J. I. (2011). Psychosocial resources: Functions, origins, and links to mental and physical health. In J. M. Olson \& M. P. Zanna (Eds.), Advances in Experimental Social Psychology (Vol. 1-57, pp. 1). New York: Academic Press.

Taylor, S. E., Lerner, J. S., Sage, R. M., Lehman, B. J., \& Seeman, T. E. (2004). Early environment, emotions, responses to stress, and health. Journal of Personality, 72, 1365-1394.

Taylor, S. E., \& Seeman, T. E. (1999). Psychosocial resources and the SES-health relationship. Annals of the New York Academy of Sciences, 896, 210-225.

Taylor, S. E., \& Stanton, A. L. (2007). Coping resources, coping processes, and mental health. Annual Review of Clinical Psychology, 3, 377-401.

Tottenham, N., \& Galván, A. (2016). Stress and the adolescent brain: Amygdala-prefrontal cortex circuitry and ventral striatum as developmental targets. Neuroscience \& Biobehavioral Reviews, 70, 217-227.

Uhart, M., Chong, R. Y., Oswald, L., Lin, P., \& Wand, G. S. (2006). Gender differences in hypothalamic-pituitary-adrenal (HPA) axis reactivity. Psychoneuroendocrinology, 31, 642-652.

Viner, R. M., Ozer, E. M., Denny, S., Marmot, M., Resnick, M., Fatusi, A., \& Currie, C. (2012). Adolescence and the social determinants of health. The Lancet, 379, 1641-1652.

Wellen, K. E., \& Hotamisligil, G. S. (2005). Inflammation, stress, and diabetes. Journal of Clinical Investigation, 115, 1111-1119. 